\title{
TITLE:
}

\section{J.C.R. Licklider's vision for the IPTO}

$\operatorname{AUTHOR}(\mathrm{S})$ :

Kita, Chigusa Ishikawa

CITATION:

Kita, Chigusa Ishikawa. J.C.R. Licklider's vision for the IPTO. IEEE ANNALS OF THE HISTORY OF COMPUTING 2003, 25(3): 62-77

\section{ISSUE DATE:}

2003

URL:

http://hdl.handle.net/2433/50514

\section{RIGHT:}

(c)2003 IEEE. Personal use of this material is permitted. However, permission to reprint/republish this material for advertising or promotional purposes or for creating new collective works for resale or redistribution to servers or lists, or to reuse any copyrighted component of this work in other works must be obtained from the IEEE. 


\title{
J.C.R. Licklider's Vision for the IPTO
}

\author{
Chigusa Ishikawa Kita \\ Kyoto University
}

\begin{abstract}
The Information Processing Techniques Office of the Advanced Research Projects Agency was founded in 1962 as a step toward realizing a flexible military command and control system. In setting the IPTO's research agenda for funding, its first director, J.C.R. Licklider, emphasized the development of time-sharing systems. This article looks at how Licklider's early vision of "a network of thinking centers" helped set the stage for the IPTO's most famous project: the Arpanet.
\end{abstract}

Joseph Carl Robnett Licklider (see Figure 1; Tables 1 and 2) is the well-known first director of the Information Processing Techniques Office (IPTO) at the Pentagon's Advanced Research Projects Agency (ARPA). As Martin Campbell-Kelly and William Aspray point out in Computer: A History of the Information Machine, IPTO support brought time-sharing into the mainstream of computing because its budget was the largest of any federal agency's for computer research. ${ }^{1,2}$ Licklider's strategy was to divide the IPTO budget among only a handful of organizations. ${ }^{3}$ Among the first nine organizations that the IPTO funded in 1963, eight were related to time-sharing. ${ }^{4}$ The fact that Licklider gave priority to time-sharing systems is, however, somewhat strange, because initially time-sharing was not even mentioned in the 1961 government-or Department of Defense (DoD)-report that led to the establishment of the IPTO. Furthermore, even if it had been mentioned, the early time-sharing systems could not support human-computer

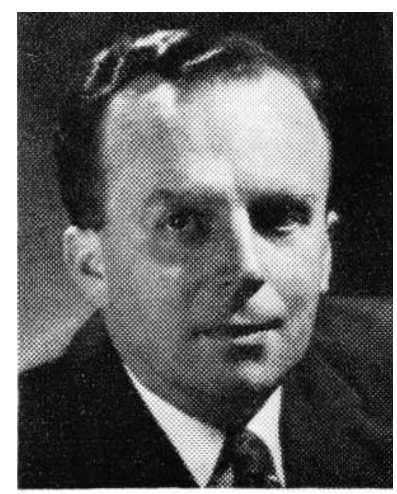

Figure 1. J.C.R. Licklider circa 1960, pictured in the IRE Transactions of Human Factors in Electronics. (Photo courtesy of the IEEE.) interaction through graphics, which was essential for the IPTO's primary objective: advancement of command and control systems. The subsequent reputation of Licklider as the progenitor of graphically oriented, interactive computing, therefore, seems inappropriate in the context of the early 1960s.

\section{IPTO's beginnings}

The IPTO was created when the Kennedy administration pressed for an improved command and control system for purposes of US defense. The Director of Defense Research and Engineering office thus charged ARPA, in June 1961, with the responsibility to develop such systems. ${ }^{5}$
ARPA requested that a study by the Institute for Defense Analyses (IDA) then be done, concerning digital computer application study, on the basis of three objectives:

1. To study command and control problems with a view toward determining criteria for the effective application of computers to command and control.

2. To postulate goals for future DOD growth in automated command and control capability and to generate guidelines that will aid future planners in specifying individual system characteristics.

3. To delineate problem areas needing accelerated research. ${ }^{6}$

The study culminated in a report, Computers in Command and Control, which was submitted to ARPA in November $1961 .{ }^{6}$ In the report, the ultimate goal for DoD was thought to be an automated command and control system. Though the study group found that the current technical feasibility of using computers was commonly overrated and "the personnel of the command must still be the dominant information processing elements of the system," ${ }^{7}$ the group listed "several areas of potentially fruitful research and development relevant to command systems." These were as follows:

a. Development of improved techniques in formulation, analysis, and programming.

b. Development of improved procedures and languages for communication between machines and their users.

c. Basic research directed toward increasing our understanding of such complex processes as pattern perception, concept formation and recognition, problem solving, learning, and decision making.

d. Research directed toward improving the 
Table 1. Personal history of J.C.R. Licklider (1915-1990), compiled on the basis of information in the J.C.R. Licklider papers at the Massachusetts Institute of Technology (MIT) Archives.

\begin{tabular}{|ll|}
\hline \multicolumn{1}{|c|}{ Year } & Event \\
\hline 1915 & Born on 11 March, St. Louis, Missouri \\
1937 & Earned AB in physics, mathematics, and psychology at Washington University, St. Louis \\
1938 & Earned AM in psychology at Washington University \\
1942 & Earned PhD in psychology at University of Rochester, New York \\
$1942-1946$ & Became research associate and research fellow in the Harvard Psycho-Acoustic Laboratory \\
$1946-1950$ & Lectured at Harvard, Dept. of Psychology \\
$1950-1957$ & Hired at MIT, associate professor in the Dept. of Electrical Engineering, (then in the Dept. of \\
& Economics and Social Science) \\
$1951-1955$ & Worked at MIT Acoustics Laboratory \\
$1952-1955$ & Consulted at the MIT Lincoln Laboratory, served as unofficial group leader \\
$1957-1962$ & Worked at Bolt, Beranek, and Newman (BBN) as vice president and headed the Psycho- \\
& Acoustics, Engineering Psychology, and Information Systems Research depts. \\
$1962-1964$ & Served at the Advanced Research Projects Agency as director of the IPTO \\
$1964-1967$ & Served at IBM as consultant to the IBM director of research \\
$1966-1967$ & Taught at MIT as visiting professor \\
$1967-1970$ & Served as director of Project MAC \\
$1967-1985$ & Taught at MIT as professor of electrical engineering, then professor of computer science \\
$1974-1975$ & Went on leave from MIT, also served a second time as director of ARPA/IPTO \\
1990 & Died, Cambridge, Massachusetts
\end{tabular}

dependability of computers and their associated hardware. ${ }^{8}$

In the IDA report, time-sharing was never mentioned. The likely reason is because time-sharing systems could not support, around 1960, the intensive use of a display at the terminals.

Indeed, Wesley Clark, designer of the advanced TX-2 computer at MIT, insisted that time-sharing had a serious limitation when he vainly opposed it in MIT's Long Range Computation Study Group in 1960. ${ }^{9}$ Ironically, Clark had already "clearly specified in 1954, in a memo entitled 'The Multi-Sequence Program Concept,' exactly how to write a subroutine capable of simultaneous execution by many different callers," and designed the I/O interrupt system into the TX-2 computer. ${ }^{10}$ Clark himself implemented the fundamental technique to allow I/O devices to share the time of the central processor, which could be used as the basis of time-sharing systems. The group headed by Clark at MIT Lincoln Laboratory, however, used the technique not for time-sharing but for the advanced use of I/O devices connected to the TX-2, to make a computer more "approachable."11 In 1963, on the TX-2, Ivan Sutherland developed Sketchpad, a digital drawing system with a light pen, which Licklider greatly admired. ${ }^{12,13}$

Strangely enough, although Licklider fully understood the importance of advanced human-machine interaction, whenever he had a choice he always leaned toward time-sharing. For example, in IPTO's early days, when Licklider decided to fund Douglas Engelbert's group at Stanford Research Institute, Licklider asked Engelbert to conduct his human-machine interaction research by using the time-sharing system. Engelbert was puzzled:

Lick[lider] moved very swiftly. By early 1963 we had a funded project. But, whereas I had proposed using a local computer and building an interactive workstation, Lick asked us instead to connect a display to the System Development Corporation's (SDC's) AN/FSQ-32 computer, on site in Santa Monica, to do our experimenting under the Q32's projected new time-sharing system. (Converting the Q32 to be a time-shared machine was SDC's IPTO project.) ... For various reasons, not uncommon in pioneering ventures, that first year was very unproductive relative to the purposes and plan of our project. ${ }^{14}$ 
Obviously, the Engelbert group's humanmachine interaction research was slowed down because of Licklider's direction. Licklider's decision runs counter to his image as a "visionary of interactive computing," which one often finds in the history of modern computing. ${ }^{15}$

Licklider explained his rationale, in economic terms, for favoring time-sharing in his paper "Artificial Intelligence, Military Intelligence, and Command and Control," which appeared in 1964's Military Information Systems. ${ }^{16,17}$ In that book, which was based on the First Congress on the Information System Sciences held in November 1962, he argued that a complex information system required large programming tasks and that a large, fast computer based on the concept of "sensibly simultaneous time sharing" can be economically used to facilitate the efforts of one programmer. ${ }^{18}$ This reasoning, however, was not sufficient to explain his inclination toward time-sharing. Because, as even Licklider himself had argued in another, 1962 paper on online man-computer communication, "in critical military systems such as SAGE [Semi-Automatic Ground Environment], the economic factor has been less restrictive and the need for man-computer interaction greater or more evident." 19 And at that time, already "the cost of computation is decreasing; it is no longer wholly uneconomic for a man to think in real time with a medium-scale computer."19

Accordingly, the development of time-sharing could be viewed as somewhat inappropriate for the DoD's new office for command and control. Licklider succeeded in arguing for the development of time-sharing officially by virtue of this economic rationale, yet he claimed that his primary goal for the IPTO was the development of interaction between humans and computers. Why would Licklider want to develop human-computer interaction through timesharing? In analyzing the reasons behind this seemingly contradictory goal, let's examine the resources with which Licklider formed the research agenda for funding the IPTO ${ }^{20}$ As will become evident, time-sharing was important to Licklider's primary concern, which he called "a thinking center." He had arrived at this concept earlier, before joining the IPTO.

\section{'A thinking center'}

Back in 1957, Licklider had joined the acoustic-consulting firm Bolt, Beranek, and Newman (BBN) in Cambridge, Massachusetts, to head a group of experimental psychologists working in acoustics. Although the group already had analog computers, Licklider asked Leo Beranek, one of BBN's founders, to buy a digital computer, which he did. ${ }^{21}$ Later, in 1959, Licklider had an opportunity to use the prototype of the Digital Equipment Corporation (DEC) PDP-1, a state-of-the-art machine that was designed after Clark's TX computers. $^{22}$ Soon, Licklider and colleagues such as BBN's Edward Fredkin and MIT's John McCarthy began developing a time-sharing system for BBN based on the PDP-1.23

The DEC PDP-1 intrigued BBN because the computer was "characterized by high speed and relatively small memory," and "its low cost means that it will not ordinarily have to be shared by a large number of users." The BBN time-sharing system was experimental, because it had initially allowed, by means of teletypewriters, only two users although that later increased to five. ${ }^{24}$ In all likelihood, Licklider and his colleagues wanted the system not out of a practical need but to confirm the possibility of scaling such a technique to a larger system.

In a series of 1961 lectures held to commemorate MIT's 100th birthday, ${ }^{25}$ Licklider served on a panel at one of the lectures, at which he discussed how time-sharing would be beneficial in making digital computers "approachable" in universities. ${ }^{26}$ In another lecture, "Time-Sharing Computer Systems" by John McCarthy, Licklider's 1960 "Man-Computer Symbiosis" essay was introduced as a "recent paper" on "the ideas concerning time-sharing systems." 27

In that paper, Licklider not only presented a new concept of a man-machine system for thinking but he also laid out a research agenda for the goal, detailing prerequisite elements such as memory hardware, programming for memory organization, computer language, and I/O devices. ${ }^{28}$ Although the reference to timesharing was not central to the paper, it was clearly presented as the first prerequisite, "Speed Mismatch between Men and Computers":

Any present-day large-scale computer is too fast and too costly for real-time cooperative thinking with one man. Clearly, for the sake of efficiency and economy, the computer must divide its time among many users. Time-sharing systems are currently under active development. There are even arrangements to keep users from "clobbering" anything but their own personal programs.

It seems reasonable to envision, for a time 10 or 15 years hence, a "thinking center" that will incorporate the functions of present-day libraries together with anticipated advances in information storage and retrieval and the symbiotic functions suggested earlier in this paper. The picture readily enlarges itself into a network of such centers, connected to one another by wide-band 
communication lines and to individual users by leased-wire services. In such a system, the cost of the gigantic memories and the sophisticated programs would be divided by the number of users. ${ }^{29}$

Licklider dealt with time-sharing as an economical matter as well as a key technology for intellectual resource sharing, "a thinking center." He even mentioned a network of such centers.

At the time of article publication, Licklider was not only participating in the development of a time-sharing system, but in the winter of 1960-1961 he had also been leading the BBN group in researching the libraries of the future. Both efforts were steps toward a realization of a thinking center. In the research agenda he laid out for the BBN research group, he encouraged the members to investigate the current status of five areas: storage and retrieval of information; memory organization; man-machine communication; language processing; and artificial intelligence (AI). ${ }^{30}$ These were the "information storage and retrieval and the symbiotic functions" whose advances were anticipated for realizing a thinking center, as he wrote in his 1960 paper.

As for implementation, BBN had launched a time-sharing service through its subsidiary company, Telcomp, in 1963, which was a "leased-wire service" cited by Licklider as the technology needed to connect a network of such centers. ${ }^{31}$ Thus, Licklider had taken steps to begin realizing his vision of an intellectual resource-sharing network just at the time he was selected as the IPTO's first director.

Against such a background, it is understandable that he envisioned a network of time-sharing systems from the very beginning of IPTO. Licklider showed his enthusiasm by describing a network in an internal 1963 ARPA memo, sometimes referred to as the "Intergalactic Computer Network memo." He addressed the memo, sent to the researchers that the IPTO funded, to the "Members and Affiliates of the Intergalactic Computer Network" in preparation for a meeting on 25 April 1963.4,32 This memo was his modestly presented agenda of computer research for funding. In the memo, Licklider explained:

It will possibly turn out, I realize, that only on rare occasions do most or all of the computers in the overall system operate together in an integrated network. It seems to me to be interesting and important, nevertheless, to develop a capability for integrated network operation.

He then went on: "Let me suppose that I am sitting at a console that includes cathode-ray-

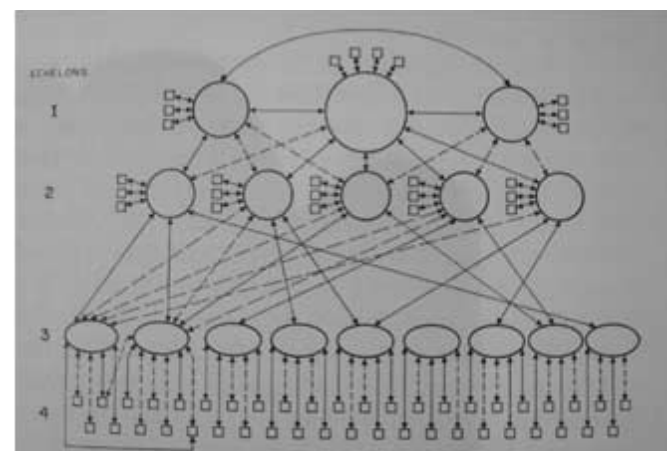

Figure 2. The procognitive system envisioned by Licklider. Licklider's explanation of the figure: "The circles and ellipses represent advanced and specialized computer systems. The squares represent man-computer interfaces, those of echelon $\mathbf{4}$ being stations or consoles for substantive users of the system. Most of the connections are switchable telecommunication lines. Those shown as solid lines represent connections that might be established at a particular moment during operation. The dotted lines are introduced to suggest other connections that could be established. ... Except in echelon 1, the number of subsystems envisioned for the projected system is very much greater than the number shown." From Libraries of the Future, 1965, p. 41. (Courtesy of the MIT Press.)

tube display, light-pen, and typewriter," and continued for three of the memo's eight pages with a detailed description of hypothetical computer network usage by an experimental psychologist. He laid out his own comprehensive picture of a thinking center here. Toward the end of the memo, he noted: "The fact is, as I see it, that the military greatly needs solutions to many or most of the problems that will arise if we tried to make good use of the facilities that are coming into existence." Thus, although there was no explanation of the direct military need for time-sharing systems or their networking, Licklider tried to convince researchers that the development of time-sharing systems would subsequently benefit the military.

His consistent concern for a network of thinking centers was seen even after his administration of the IPTO had ended. In Licklider's only book, Libraries of the Future, the central concept of a "procognitive system" (see Figure 2) extended his vision of such a network. ${ }^{33}$ In the book, he explained that this network consisted of four echelons of subsystems all based on a time-sharing technique, and he pointed to IPTO-funded time-sharing systems at MIT, the Carnegie Institute of Technology, System Development Corporation, RAND 


\begin{abstract}
About SAGE
The Semi-Automatic Ground Environment (SAGE) was a command and control network for air defense, designed to coordinate all air defense components by a digital computer at individual Direction Centers. It was one of the biggest postwar air defense projects, officially beginning in $1954.1^{1}$ Although SAGE as an air defense system for bombers was already out of date when it became operational in 1958 because of the Intercontinental Ballistic Missile (ICBM), it had a great impact on military system design, computer research, and industry. ${ }^{2}$ In the context of human factors in man-machine systems research, SAGE was also one of the most important achievements. As the name indicates, SAGE was a semiautomatic system that included human elements, such as computer operators who helped with SAGE procedures and commanders who conducted the decision-making process. As Kenneth Schaffel has written in his book on the history of air defense, in the early 1950s when the SAGE project was launched, industrial automation applications were new and military applications were only dimly perceived. ${ }^{3}$ But the new air defense system was intended to be automated, just like other industrial applications, because manual procedures for transmitting military information through telephone and teletype systems lacked speed and precision. For this reason, computers were crucial. At the same time, as MIT's professor George Valley, who headed the Air Defense System Engineering Committee of the US Air Force Scientific Advisory Board (1950-1952), noted in his memoir, there was a controversy between analog and digital usage. The researchers at MIT chose digital computers because by comparison analog computers had serious limitations. ${ }^{4}$
\end{abstract}

\section{References and notes}

1. On this point, see for example, S.I. Schwartz, ed., Atomic Audit: The Costs and Consequences of U.S. Nuclear Weapons since 1940, chapter 4: "Defending against the Bomb," Brookings Institution Press, 1998. For the general history of SAGE, see, in particular: Annals of History of Computing, special issue on SAGE, vol. 5, no. 4, Oct.-Dec. 1983; G.E. Valley Jr., "How the SAGE Development Began," Annals of History of Computing, vol. 7, no. 3, July-Sept. 1985, pp. 196-226; K. Schaffel, The Emerging Shield: The Air Force and the Evolution of Continental Air Defense, 1945-1960, Office of Air Force History, US Air Force, Washington, D.C., 1991.

2. See, for example, an excellent historical work on this subject: K.D. Redmond and T.M. Smith, From Whirlwind to MITRE: The R\&D Story of the SAGE Air Defense Computer, MIT Press, 2000.

3. Schaffel, The Emerging Shield, p. 150.

4. Valley, "How the SAGE Development Began," pp. 220-221.

Corporation, and $\mathrm{BBN}$ as the best schemata to think about the third and fourth layers of the network. ${ }^{34}$

From these facts, we can see Licklider added time-sharing to the IPTO agenda to realize his vision of a network of thinking centers, and he even placed priority on it. But how would the picture of a thinking center readily enlarge itself as a network of such centers?

\section{'The Truly SAGE System ...'}

The archived J.C.R. Licklider papers include an interesting typed 1957 manuscript (containing a number of hand-written corrections): "The Truly SAGE System or Toward a Man-Machine System for Thinking." 35 It demonstrates that Licklider's network of thinking centers was a transformation of SAGE as an advanced information network. To understand its historical meaning, we need to examine Licklider's relationship to the 1950s SAGE project (see the "About SAGE" sidebar).

Licklider's relationship with SAGE started in 1951 when, as an associate professor at MIT, he was chosen to be "a token psychologist" 36 in Project Charles, an MIT project established to examine the possibility of an improved air defense system. ${ }^{37}$ The MIT Lincoln Laboratory was established in the early 1950s with the primary mission of developing a national air defense system. One of the groups was psychology. Although Licklider was officially a consultant to the psychology group at Lincoln Laboratory, he worked closely with George Miller, its group leader, in forming the group that examined how to detect information from the analog graphical data obtained from radar.

The group collaborated with electrical engineers on data transmission and with engineers from Polaroid Corporation on analog graphical technology, but it had almost no direct connection to the digital computer developments at MIT Lincoln Laboratory. ${ }^{38}$ However, Licklider had "an opportunity with Lincoln Laboratory to hear of computers and radar sets and communications." ${ }^{36}$ As Licklider often mentioned, his exposure to advanced digital computers at the laboratory in the late 1950 s was a crucial experience for him in forming a vision of their advanced usage in the future. ${ }^{39}$

The principal architect of TX computers at Lincoln Laboratory, Wesley Clark, recalls introducing Licklider to one of the computers (in the quote, "LINC" is the name of the small computer Clark designed in the early 1960s):

I had simply demonstrated its use and powerful displays to him, and had expected him to draw his own conclusions about the great value of interacting with a computer directly. I had learned this "on-line" style of operation on Whirlwind and the Memory Test Computer (MTC), and I designed the TX-0, the TX-2 and, of course, the LINC for use in this same, directly interactive manner. All of these computers had display scopes, and "interaction" meant making extensive use of them. Lick[lider] saw how we did all this and was clearly intrigued. Like many 
other visitors, he understood the enormous value of using computers directly and thought to emulate the way we did things at Lincoln. ${ }^{40}$

As Clark notes, it was at this time that Licklider recognized the potential for extensively using displays.

Around the time that he first saw the TX-2, Licklider also had some interaction in meetings with Lincoln Laboratory's communications techniques group, which conducted research on pattern recognition and was headed by Oliver Selfridge. ${ }^{41}$ Selfridge and G.P. Dinneen had presented papers on pattern recognition at the Western Joint Computer Conference in 1955. ${ }^{42}$ At the same conference session, Clark also presented a paper on pattern recognition. ${ }^{43}$ Thus, through his associations with colleagues at Lincoln Laboratory, we can assume Licklider acquired knowledge of pattern recognition by digital computers. With such knowledge of advanced computing, Licklider even began to think about an advanced information system through the scheme of SAGE as a whole.

As Licklider wrote in "The Truly SAGE System," the aim of the 1957 paper was "to suggest a kind of system that seems desirable and reasonable from a psychological point of view and not totally unfeasible from a psychologist's approximation of an engineering point of view." 44 This paper indicates that Licklider conceived of an idea for "a network of thinking centers" through SAGE and added some new features. ${ }^{45}$ The title of Licklider's manuscript hints that SAGE was not sage enough for what Licklider envisioned despite the name, but he did not fiercely criticize SAGE. On the contrary, he maintained his close connection with the Air Force (SAGE's developers) in the 1950s and early 1960s. ${ }^{46}$ Moreover, he wrote this paper as a National Academy of Science-Air Research and Development Command (NAS-ARDC) Special Study paper. Licklider later acknowledged ARDC as the main funding source of the "Man-Computer Symbiosis" paper in 1960.47

The paper contains 10 parts (see Figure 3 ). In the first part, Licklider wrote that he was concerned with finding a way to "improve the quality or efficiency of scientific and technical thinking." 48 The paper's framework proposes the effective use of the computer for a system of networked information centers. ${ }^{49}$ The first four parts explain the goals of the network and provide a picture of the system. The next part, "Steps Toward Realization," presents the four steps (which, in his original outline, are listed as parts but which are actually subparts) needed for

\author{
"The Need" \\ "The Room for Improvement" \\ "The System" \\ "Hypothetical Picture of a System in Operation" \\ "Steps Toward Realization" \\ "Study of Creative Thinking" \\ "Research and Development on Mechanical Data-Processing \\ Techniques" \\ "Artificial Intelligence" \\ "Development of a Small, Experimental System" \\ "Variations"
}

Figure 3. Outline of Licklider's 1957 paper, "The Truly SAGE System or Toward a Man-Machine System for Thinking."

realization and describes each in detail; the last short part describes the system's potential.

The use of the system as an information center is portrayed as a general application of SAGE. In each center, "there is of course a large-scale digital computer with a very extensive memory," and "the centers for related fields are connected one with another by telecommunication channels." 50 There are four modes of communication between man and machine in the system. First, human operators can simply speak into microphones. Second, there is a combination display and control having a large, flat surface onto which material is projected and the operators can write with a pencil or stylus. Third, the operators can put graphical information (such as curves and functions) into the computer and relate the information so introduced to graphical information presented by the computer. Fourth, the operators can use "typing or type-writer-perhaps one that is also used as a computer-output device." 51 Among these modes, the last three were achieved on the SAGE consoles, but Licklider added a new feature of speech recognition that was clearly beyond the 1950s state of the art. Later, in his "Man-Computer Symbiosis" paper (1960), Licklider also described how "desirable" and "feasible" speech communication between man and machine could be in section E-3: "Automatic Speech Production and Recognition." 28

The proposed computing style in each center is online use by multiple users based on a time-sharing technique:

The computer is operated on a time-sharing basis by a number of people. The arrangements for displaying information to the people are highly developed. They include digital-analogue converters, curve plotters, large-screen cathode-ray tubes, automatic typing or printing machines, and loudspeakers. ${ }^{51}$ 
It is notable that he mentioned time-sharing by multiple people here, because Licklider's 1957 paper is one of the earliest written records mentioning time-sharing in this sense. Although this concept of time-sharing is usually associated with John McCarthy, who wrote specifically about it in a 1959 memo at MIT,, 52 the "Truly SAGE" paper indicates that Licklider had already used the term in the summer of $1957 .{ }^{53}$ It was possible for Licklider to have been exposed to the phrase time-sharing at the SAGE project, although there it was used to describe the SAGE program's cyclic scheduling process. ${ }^{54}$ As J.A.N. Lee writes in the introduction to the Annals' special issue on time-sharing and interactive computing, the phrase time-sharing (sometimes hyphenated or capitalized) was used as a technical term throughout the mid1950 s to the mid-1960s with different meanings, and the diversity of its usage even became controversial in the mid-1960s. ${ }^{55,56}$ But at least Licklider's intention to push its development was clear in his 1957 paper. For Licklider, timesharing was a technique to allow users simultaneous multiple access and one that was needed to share the information stored in the largescale computer at a thinking center.

The essential point is that, both in SAGE and in a network of thinking centers, computers are networked and used for data processing and storage, and the computing style is online. Like SAGE, Licklider's picture of "a thinking center" could "readily enlarge itself into a network of such centers." 29

\section{Against 'artificial intelligence'}

As we have seen, Licklider's network of thinking centers was inspired by SAGE. But what about the tendency toward automation as seen in SAGE?

The title of his 1957 paper $^{35}$ suggests that Licklider wanted a truly semiautomatic system that contained human elements. In the paper he indicated four categories of humans in the system: scientists, engineers, and other "thinkers"; "impedance matchers"; maintenance personnel; and programmers. ${ }^{51}$ The impedance matchers were people who helped the thinkers in operating the equipment. Historically, most of the research on human factors in man-machine systems was about machines and the humans in the last three categories. Machines needed humans to help their procedures.

The SAGE designers tried to realize automation by gathering information from various sources and presenting the data as a composite picture of the air situation as it developed, but it was in many senses semiautomatic. It needed many operators. In SAGE, there was a transition from the old type of manual system of using hand plotting or voice communication for transferring data to the use of automation. In 1958, Licklider criticized SAGE's insufficiency in realizing the level of automation originally proposed:

The main experience we have had with a largescale man-machine system for situation analysis and control has been provided by the SAGE system. But it does not, either, help much to convey the conception we have in mind. The SAGE system was conceived of originally as being very largely automatic. The numerous human operators have been brought into SAGE mainly to handle tasks that turned out not to be practicable for the computer. It is therefore too much a matter of men aiding the machine, and not enough a matter of true man-computer symbiosis, to give us a preview of the Air Force information-processing and control systems that we hope will exist in the future. ${ }^{57}$

This criticism also appeared in his 1960 paper generalizing the concept of man-computer symbiosis from its specific application for Air Force systems. ${ }^{58}$ Accordingly, Licklider did not deny the need to automate functions that helped the procedure of computers and even encouraged it for future man-machine systems. But in SAGE, there were thinkers: commanders and weapons directors. Licklider thought that the most important human component in his "truly SAGE system" was the thinkers:

The scientists and engineers combine their cerebral data-processing with the facilities of the machine to constitute a more effective system than either the human or the mechanical parts alone could make. ${ }^{59}$

At that time, there was another general application of SAGE, this one by IBM: SemiAutomatic Business Research Environment (Sabre), the online airplane reservation network system of American Airlines. ${ }^{60}$ Sabre was basically an advanced automation of the preexistent human-operated information network system. ${ }^{61}$ All the users of the Sabre system followed the same preestablished procedure, although in a network of thinking centers, users would apply the information in many different ways. In this sense, Sabre was a commercial application that made SAGE simpler and stabler through "IBM's mature and well-seasoned engineering approach derived from its SAGE 
experience." ${ }^{62}$ By contrast, a network of thinking centers would be more complex and advanced than SAGE. In Sabre, users were just like the radar in SAGE that fed a piece of information into a preestablished procedure. Sabre essentially automated the functional equivalent of the SAGE commander to, in this case, decide which seat should be reserved or cancelled. But in a network of thinking centers there would be many thinkers to input some data and use the system information in their thinking processes as the commanders in the SAGE system did. Furthermore, the thinkers in Licklider's thinking centers could use the whole system simultaneously in different ways, whereas SAGE had a single air-defense procedure. In this sense, Licklider did not share a tendency toward complete automation that would include the decision-making process, while Sabre did. In fact, the direction Sabre took seemed promising at the time, because AI was expected to be a key technology for the automation of complex man-machine systems. ${ }^{63}$ Licklider did not share this view; indeed, he employed the phrase "man-computer symbiosis" to express his opposition to automation.

\section{Man-computer symbiosis}

Well before the term artificial intelligence was born, comparisons between a computer and a human brain had already been made. Even the usage of the term computer implied a personification of a machine, because the old usage meant humans, not machines. Fittingly, the popular press often employed expressions such as "giant brain" or "electronic brain" throughout the 1950s and 1960s. ${ }^{64}$

Licklider showed sympathy for research in this area in the "Artificial Intelligence" section in his 1957 manuscript:

There is little reason to restrict either the man or the machine to what, at the outset, appears to be his zone. In fact, the problem of coupling between the man and the machine would be greatly simplified if the machine could be developed in part in man's image. It is desirable, therefore, to explore the possibilities of the field of research currently designated by the terms artificial intelligence and self-organizing automata. That study and the study of human thinking and perceiving should be mutually facilitating. ${ }^{65}$

Licklider did in fact interact with people who participated in the Dartmouth Summer Research Project on Artificial Intelligence in 1956, where the phrase "artificial intelligence, or AI" seems to have been officially used for the first time. For example, Marvin Minsky, one of the original members of the summer project, listed Licklider as one of his mentors. ${ }^{66}$ In the late 1940s, Minsky was one of the students in Licklider's seminar while Licklider was affiliated with the Harvard Psycho-Acoustics Laboratory. ${ }^{67}$ They often built electronic devices together for experiments on theories of learning. ${ }^{68}$ According to Minsky, Licklider built "a wonderful machine" that "could recognize the word 'watermelon' no matter who said it in no matter what sentence" in the early 1950s. ${ }^{69}$ And when Licklider gave a talk about his psychological research on acoustics at the 7th Macy conference on "The Feedback Mechanisms and Circular Causal Systems in Biological and Social Systems," Claude Shannon, who had also been on the Dartmouth project, was the speaker following Licklider, and they both participated in discussions together at the meeting. ${ }^{70}$

Other researchers related to the Dartmouth project with whose paths Licklider kept crossing included Oliver Selfridge, who had been an assistant to Norbert Wiener, the well-known mathematician who authored Cybernetics, and carried on the research on pattern recognition at MIT Lincoln Laboratory where Licklider had spent some time with him. Another participant, Nathaniel Rochester of IBM, had programmed a neural network model on the computer. This work was said to apply Donald O. Hebb's The Organization of Behavior (1949), and the Rochester group was inspired by Licklider's talk on Hebb's theory in $1952 .{ }^{71}$ In fact, in the preface to his book, Hebb noted that Licklider was one of the scholars he was indebted to "for painstaking and detailed criticism of a large part of the manuscript, improving both matter and style."72

In his "Symbiosis" paper, Licklider listed 13 papers on "theorem proving, problem-solving, chess-playing, and pattern recognizing programs" as best papers on AI including those by researchers whom he knew. He continued as follows:

In fact, it seems worthwhile to avoid arguing with (other [than the researchers whose papers he listed]) enthusiasts for artificial intelligence by conceding dominance in the distant future of cerebration to machines alone. There will nevertheless be a fairly long interim during which the main intellectual advances will be made by men and computers working together in intimate association. ${ }^{73}$

Apparently, Licklider tried to differentiate his man-machine symbiosis concept from AI 
concerning the possibility of fully automating a man-machine system that included a heuristic human brain procedure. This point was central to his 1960 paper.

Licklider published "Man-Computer Symbiosis" as the first article in the inaugural issue of the IRE Transactions on Human Factors in Electronics, which appeared in March 1960. The journal was one of the newly established periodicals of human factors research at the time. In the 1950s, a newly emerging research area involved designing complex systems that included humans as elements. Such systems were usually called man-machine systems. The main man-machine systems were for military use, but there were also requirements in industries for "the production of a commodity or the construction of a facility." 74

A field of specialization concentrating on solving the problems that occurred between man and machine had evolved during World War II, as has been described in the official history of the Office of Scientific Research and Development (OSRD). ${ }^{75}$ The new interdisciplinary area for handling problems involving "man as a system component" 76 was called by various names by 1960, such as human factors in engineering, human engineering, engineering psychology, biomechanics, applied experimental psychology, and ergonomics, among others, as mentioned in the preface of McCormick's well-known textbook, Human Engineering. ${ }^{77}$ As he wrote in this 1957 book, McCormick noticed there were many who did not like the term human engineering but he adopted it because it was the most popular expression, even though "not adequately descriptive of the field." In 1957, the American Psychological Association declared the formation of the new division of the Society of Engineering Psychologists in an effort to form an academic area gathering their research results on the human element in a man-machine system. ${ }^{78}$

Licklider was so enthusiastic about the establishment of the academic field that he served on the editorial board of another newly published periodical, Human Factors, in the late 1950s and became the fourth president of the Society of Engineering Psychologists in 1961.79,80 Thus Licklider's "Man-Computer Symbiosis" clearly reflected important elements of the new area of human factors research.

The "Symbiosis" paper suggested that a computer could be an ideal partner for human beings in "formulative thinking," which was preferable to a completely automated man-machine system. The paper then provided an agenda for the research necessary to accomplish the goal of such interaction between men and computing machines. At that time, researchers treated automation as an important objective for man-machine systems. If such a system were fully automated, humans would disappear completely, to be replaced by computers carrying out all tasks, even intellectual tasks formerly considered reserved for humans. Man would no longer be a component of man-machine systems. Licklider tried to redirect the trend, and to this end he used the phrase man-computer symbiosis.

There is also an interesting document in the archived Licklider papers, entitled: "Man-Computer Symbiosis: Part of the Oral Report of the 1958 NAS-ARDC Special Study, Presented on Behalf of the Committee on the Roles of Men in Future Air Force Systems, 20-21 November 1958." ${ }^{81}$ This seems to be the first paper in which Licklider used the phrase man-computer symbiosis. It demonstrates how Licklider explained the importance of research on man-computer symbiosis to the Air Force, the main organization that funded such research. In his 1958 "Man-Computer Symbiosis" report, Licklider mentioned another report: "Report of the Committee on the Roles of Men in Future Air Force Systems." He wrote: "Since there is not time to report on all those topics, I shall select just one of them-actually one subtopic - and concentrate on it. We have been referring to it as man-computer symbiosis." 82

From this, we know that Licklider coined the phrase man-computer symbiosis in committee discussions and had been using it at least as early as the summer of 1958, in the context of the military application of man-machine systems in the future.

Licklider started the early 1958 report in the style of popular science fiction: "[T]he President pressed the golden button. The wheels whirred, the lights flashed, the display panel came aglow, and the computer announced: 'I am glad that you asked me that question.'” Right after this humorous beginning, Licklider rejected the image of complete automation through computers. ${ }^{82}$ He doubted the adequacy of an image of self-thinking machines caused by the popular understandings of AI. At that time, the phrase man-computer symbiosis was an effective phrase to call attention to his argument against full automation: that there be a partnership between human and computer. He denied the early realization of complete automation in "intelligence data processing, mission planning, battle control and assessment." 83 Licklider argued that it would need 10 to 20 years for "developments in artificial intelli- 
gence to make it possible for machines alone to do much thinking or problem solving of military significance." And he confirmed the need for research of "man-machine communication" because there would remain human elements in man-machine systems in the near future. ${ }^{84}$ This estimation was also referred to in his 1960 paper, where Licklider even mentioned that it might take far longer, 500 years, for the development of applicable AI. ${ }^{73}$

Once he began to emphasize the importance of man-computer symbiosis, he had to defend his research agenda to the funding source, the Air Force. In 1961, Licklider wrote "The Cerebral Frontier" as a "draft of a report to the Basic Research Panel of the Air Force Scientific Advisory Board by the Committee on Artificial Intelligences, Bionics, and Man-Computer Symbiosis." 85 The Air Force was concerned with the future of man-machine systems, and there were at least three agendas to advance them: AI, bionics, and man-computer symbiosis. In this competitive situation, he tried to emphasize that his research agenda was the most practical. Admitting some overlap among the three agendas, Licklider recommended the funding of both man-computer symbiosis and AI, because there were "intelligent and dedicated young research workers, trained in contributory disciplines and qualified for the task, who are eager to explore and assimilate the cerebral frontier." By "young research workers" he obviously meant Minsky and McCarthy, and others who had helped his research on libraries of the future at BBN.

\section{Directing IPTO}

When Licklider became the first director of the IPTO, the fundamental military concern with AI was its possible application for automating command and control system. In the 1961 IDA report that spawned IPTO, the words automated and automation were frequently used, and the report's authors investigated AI's potential as a key technology for automating tasks such as problem solving, selfmodifying or optimizing systems, and decision making. ${ }^{86}$ Although different from his agenda for man-machine systems, the field of AI represented a good opportunity for Licklider, who had been trying to find funding sources for his "young research workers"-AI was a likely project for IPTO funding.

However, Licklider carefully avoided promising an early direct application for automated command and control systems from this funding. In his 1964 paper "Artificial Intelligence, Military Intelligence, and Command and
Control," Licklider did not say that AI would be a key for an automated military system, but that it would "come to grips with some of the problems that are basic in command and control." He reasoned as follows:

The prospect that research in artificial intelligence may progress in a definite and substantial way is favored by the fact that the tool of dynamic representation exists, that it can be developed greatly beyond its present state, and that research recognize its value. The prospect that their work may have practical bearing upon command and control and military intelligence is favored by the fact that researchers in artificial intelligence are working on problems that happen to be relevant and basic and that the tools they are developing promise to be useful in military information processing. ${ }^{87}$

Among Licklider's first nine funded organizations in 1963, four received budgets for AI: Allen Newell's group at Carnegie Institute of Technology, McCarthy's group at Stanford, the Systems Development Corp. for heuristic programming and theory of computation, and Minsky's group at MIT for recursive functions, symbolic manipulations, heuristics, and problem-solving in Project MAC. ${ }^{88}$ Note that all of the organizations were working on time-sharing at the same time, and the AI that Licklider funded was not outside his thinking-center scheme; rather, it would support his ideas by potentially improving man-computer interaction by means of a console.

We can conclude that in determining what the IPTO should fund, Licklider's inclination toward developing a network of thinking centers played a key role in his overall agenda, albeit unofficially. Licklider instead directed the IPTO to officially fund time-sharing projects (which could serve as the basis for thinking-center networks) and AI (which could improve manmachine communication required in those networks). On one level, Licklider established the IPTO agenda to fund projects that would fulfill the military's need for improved command and control systems, but on another level, he continued pursuing his personal research agenda for the network of thinking centers.

\section{IPTO after Licklider's departure}

The direction that Licklider initially set for the IPTO was strongly affected by his own research interests. However, as Arthur Norberg and Judy O'Neill show in Transforming Computer Technology, important IPTO priorities included graphics and networking. ${ }^{89}$ The latter two ini- 
tiatives were not yet fixed during Licklider's directorship. In recent years, with an increased focus on how the networks of computers concept originated, historians and writers tend to refer to Licklider's role as an inspiration for the Arpanet, irrespective of their approach. ${ }^{90}$ But, in fact, neither Licklider's vision for thinking centers nor his call for an intergalactic computer network directly formed the IPTO agenda for funding networking projects, as we'll see.

Licklider directed the IPTO for two years (1962-1964). Although his IPTO research priorities initially favored time-sharing over human-computer interaction, Licklider appreciated the need to fund man-machine interaction research. Because he had high praise for Ivan Sutherland's work at MIT on man-machine communication through graphics, he asked Sutherland to become the IPTO's second director. As the IDA report had originally explained, the development of "man-computer communication" was crucial to the US military's future command and control system, so it was logical for the IPTO to emphasize its importance.

Through Sutherland, the IPTO became more focused on the advancement of man-machine communications, especially in the graphics area so urgently needed for future military command and control. During his directorship (1964-1966), Sutherland set an agenda firmly establishing computer graphics as a research focus. ${ }^{91}$ Consequently, through his research funding from the IPTO, Larry Roberts-who had worked in the computer graphics area at MIT Lincoln Laboratory-began working on the time-sharing scheme as it related to graphics. ${ }^{92}$ Roberts wrote about the quality of displays connected to time-sharing systems in a 1965 paper, "Graphical Communication in a Time-Sharing Environment":

It is generally acknowledged today that display equipment is a powerful component for facilitating man-machine communications in computer systems. The advent of large-scale time-sharing has made many forms of on-line operation, which previously were extremely inefficient, economically feasible for the first time. This has resulted in renewed interest in low-cost displays to improve the ease and speed of interaction. Although there is considerable agreement on the value of graphical techniques, there is wide divergence in the approaches to designing display consoles. This variety reflects not only the necessary differences in application requirements but the limited operating experience of designers as well. In particular, extensive experience in on-line graphics on the Lincoln Laboratory TX-2 Computer has demonstrated that the common tendency to sacrifice performance for the sake of cost reduction is a dangerous one. ${ }^{93}$

Even in 1965, the conflict between timesharing concepts and high-quality manmachine communications was evident. But through the effort of Roberts and others the two research initiatives coexisted to some extent. In directing the IPTO funding of Roberts' research, Sutherland integrated two previously separate funding priorities: timesharing and computer graphics.

Although both Licklider and Sutherland saw potential in man-computer communication, Sutherland did not share Licklider's skepticism about the complete automation of a man-machine system. As the second director of the IPTO, Sutherland argued:

The future of on-line systems depends a great deal upon the future of off-line systems. There is a lot of talk these days about a semi-automated mathematical laboratory in which a mathematician could prove theorems that he could not prove without computer assistance. How about having the computer prove the theorems all by itself? Suppose the artificial intelligence people make a machine which can, in fact, prove new theorems all by itself. What then becomes of our semi-automated mathematical laboratory? It's useless. ... What I am predicting is that today's interest in systems in which a man and a machine get together on-line will be replaced in the distant future by interest in systems in which a computer gets directly on-line with the real world, sensing and interacting with it directly through transducers. The "real world" with which such systems interact will include human beings, of course. ${ }^{94}$

Sutherland dismissed the concept of "symbiotic" systems that should be almost, but not completely, automated. Instead, he tried to redirect the IPTO funding agenda to support advanced hardware design projects, inasmuch as the advanced design of TX-2 had stimulated him to produce Sketchpad. ${ }^{95,96}$ In fact, the support for hardware research was recommended in the original IDA report by which the IPTO was formed. Although historians viewed this direction "almost as a digression" for the IPTO, at the time it was a reasonable redirection. ${ }^{97}$

On the matter of a computer network, Sutherland directed and funded a network experiment at UCLA, and he "noted time sharing's effect on the sharing of programs and 
other files among users of the same system." 98 Around the same time, Sutherland wrote:

\begin{abstract}
We have only just begun to work with computers as communication media between people. Today, by linking remote stations, we can allow one person to "look over the shoulder" of another through a computer. We have yet to combine the functions of the design system and the inquiry system. The ability of many people in widely separated locations to know exactly what is going on has already proved practical in the airline reservation system. It must be included in our computer-assisted design system. ${ }^{99}$
\end{abstract}

Clearly, Sutherland had high regard for other trends outside the IPTO, such as Sabre, and he described the networking of computers, including these attempts, as "communication media between people."

The research agenda for time-sharing systems earlier set by Licklider now began to generate some elaborate, large-scale systems during Sutherland's directorship. However, these systems that the IPTO had funded were complicated and unwieldy and had many problems. ${ }^{100}$ Around the same time, relatively simple time-sharing systems first became commercially available outside the IPTO world. As Norberg and O'Neill point out, "most computer manufacturers had announced and were working on time-sharing systems by 1965."100 The business area of time-sharing services in particular was growing rapidly from the mid1960s on. ${ }^{101}$ As Thomas Hughes notes in Rescuing Prometheus, this trend-the distribution of computing power-is analogous to the evolution of electricity distribution. ${ }^{102}$ But, at the same time, time-sharing systems were not necessarily favored by all computer users. Small computers, for instance, began to emerge in the 1960s, and there was a conflict over which approach companies should take in choosing computing facilities, as evidenced in popular magazines such as Computers and Automation. ${ }^{103}$

The IPTO acquired its third director in 1966. At that time, as disadvantages of time-sharing systems began to be debated publicly, director Robert Taylor tried to continue funding of time-sharing. He argued in 1967:

All time-sharing systems give promise of an economic advantage gained through one computer system serving more than one on-line user. Furthermore, a computer system large enough to serve a number of simultaneous users provides, for any one user, more storage, computational power and convenience than he could expect to afford on his own stand-alone machine. ${ }^{104}$

By the same token, he began to emphasize the merits of a time-sharing system: a community of users communicating through computer consoles. ${ }^{105}$ To pursue this potential, he initiated the network project that led to the Arpanet. At that time, computers and telecommunications were often discussed together, and computer networks were constructed by connecting the same kind of computers. But Taylor wanted the project to connect communities to make the reason for the IPTO's support of timesharing more meaningful, independently from Licklider's earlier agenda of a network of thinking centers. Consequently, the IPTO wanted a network experiment between the most geographically distant organizations it funded: MIT Lincoln Laboratory (Massachusetts) and SDC (California), and asked Roberts to take charge because he was managing TX-2 at Lincoln. ${ }^{106}$

According to Roberts, he had been well aware of Licklider's enthusiasm for networking time-sharing systems, but when the IPTO sought his expertise in 1966, Roberts declined; he was more interested in computer graphics. Ultimately, however, Roberts was compelled to join the IPTO to direct the networking project, and the IPTO agenda for computer networking was set in motion at last. ${ }^{107}$

Roberts' approach to the network experiment differed from what Licklider had originally envisioned. Unlike the centralized time-sharing systems at the heart of Licklider's networking concept, the Arpanet was designed as a distributed network, and Roberts integrated the former directors' visions into an agenda for a resource sharing network. ${ }^{108}$

We can conclude that the IPTO agenda for networking was backed by the time-sharing agenda set by Licklider, though it did not precisely follow his picture of a network of thinking centers. As we know, the Arpanet became a basis of the backbone of today's Internet. Of course, the Internet has been the dynamic force in integrating multiple separate networks into a network system, so we cannot point out only one origin. But we can say that Licklider's original vision of intellectual resource sharing through a network of online databases stored in digital computers has been historically realized in today's Internet.

\section{Acknowledgments}

On the revision process, the comments and advice of the reviewers were helpful in making 
this article better, and I am greatly indebted to Michael S. Mahoney for his kindness in reading, and commenting on, this article.

\section{References and notes}

1. M. Campbell-Kelly and W. Aspray, Computer: A History of the Information Machine, Basic Books, 1996, p. 212.

2. Committee on Innovations in Computing and Communications: Lessons from History, Computer Science and Telecommunications Board, Commission on Physical Sciences, Mathematics, and Applications, National Research Council, Funding a Revolution: Government Support for Computing Research, National Academy Press, 1999, p. 56.

3. A.L. Norberg and J.E. O'Neill, Transforming Computer Technology: Information Processing for the Pentagon, 1962-1986, Johns Hopkins Univ. Press, 1996, pp. 58-59.

4. According to the ARPA internal memo directed to the organization Licklider funded, from J.C.R. Licklider to members and affiliates of the Intergalactic Computer Network, in J.C.R. Licklider Papers (MC 499), Inst. Archives and Special Collections, Mass. Inst. of Technology Libraries, Cambridge, Mass. (hereafter referred to as Licklider Papers at MIT Libraries), box 7, folder "1963," the distribution is for SDC (System Development Corp.); Stanford Research Inst.; Stanford Univ.; Univ. of California (Berkeley); Univ. of California (Los Angeles); Carnegie Inst. of Technology; Information Int'I Inc.; MIT; Thompson-Ramo-Woolridge. The fact that the eight organizations were related to timesharing was confirmed through Norberg and O'Neill, Transforming Computing Technology, pp. 102-103 and accompanying references.

5. Norberg and O'Neill, Transforming Computing Technology, pp. 9-10.

6. Inst. for Defense Analyses, Research and Eng. Support Division, Computers in Command and Control, tech. report 61-12, Nov. 1961, p. 1.

7. Ibid., p. 2.

8. Ibid., p. 62.

9. Norberg and O'Neil, Transforming Computer Technology, pp. 84-85; W. Clark, "The LINC Was Early and Small," A History of Personal Workstations, A. Goldberg, ed., ACM Press, 1988, p. 358.

10. E. Fredkin, "The Time Sharing of Computers," Computers and Automation, Nov. 1963, vol. 12, no. 11. p. 12.

11. I.E. Sutherland, Sketchpad: A Man-Machine Graphical Communication System, master's thesis, Dept. of Electrical Eng., MIT, Jan. 1963, MIT theses, no. 1963-10, chapter 2: "History of Sketchpad," p. 24.

12. I.E. Sutherland, "Sketchpad: A Man-Machine Graphical Communication System," AFIPS Proc. Spring Joint Computer Conf., Spartan Books, vol. 23, 1963, pp. 329-345.
13. F. Gruenberger, ed., Computer Graphics: Utility/Production/Art, Thompson Book Co., 1967, pp. 44-45.

14. D.C. Engelbert, "The Augmented Knowledge Workshop," A History of Personal Workstations, A. Goldberg, ed., ACM Press, 1988, pp. 191-192.

15. See, for example, H. Rheingold, Tools for Thought: The People and Ideas behind the Next Computer Revolution, Simon \& Schuster, 1985, chapter 7; Norberg and O'Neill, Transforming Computer Technology, pp. 26-30; Campbell-Kelly and Aspray, Computer, pp. 212-215; P.E. Ceruzzi, A History of Modern Computing, MIT Press, 1998, p. 306. Also see Licklider's biographical history: M.M. Waldrop, The Dream Machine: J.C.R. Licklider and the Revolution That Made Computer Personal, Viking, 2001.

16. E. Bennet, J. Degan, and J. Spiegel, eds., Military Information Systems, Frederick A. Praeger, 1964, preface, p. ix.

17. J.C.R. Licklider, "Artificial Intelligence, Military Intelligence, and Command and Control," Military Information Systems, 1964, pp. 118-133.

18. Ibid., pp. 123-124.

19. J.C.R. Licklider and W.E. Clark, "On-Line Man-Computer Communication," AFIPS Proc. 1962 Spring Joint Computer Conf., Spartan Books, vol. 21, May 1962, p. 113.

20. In relation to the term of agenda, see M.S. Mahoney, "The Structures of Computation," The First Computers: History and Architectures, R. Rojas and U. Hashagen, eds., MIT Press, 2000, pp. 2021: "The agenda of a field consists of what its practitioners agree ought to be done, a consensus concerning the problems of the field, their order of importance or priority, the means of solving them, and perhaps most importantly, what constitutes a solution."

21. L. Beranek, "Roots of the Internet: A Personal History," The Massachusetts Historical Rev., vol. 2, 2000, pp. 57-59.

22. In 1959, the PDP-1 prototype came to BBN before its official release. See, for example, "The Project MAC Interviews," Annals of the History of Computing, vol. 14, no. 2, Apr.-June 1992, pp. 16-17. A photo of the prototype can been seen in G. Bell, J.C. Mudge, and J.E. McNamara, Computer Engineering: A DEC View of Hardware Systems Design, Digital Press, 1978, p. 135. The influence of TX-0 and TX-2 on PDP-1 is described in chapter 6, "The PDP-1 and Other 18-Bit Computers," pp. 123-129.

23. L. Beranek, "Roots of the Internet: A Personal History," p. 60.

24. J. McCarthy et al., "A Time-Sharing Debugging System for a Small Computer," AFIPS Proc. 1963 Spring Joint Computer Conf., Spartan Books, vol. 23, p. 56.

25. M. Greenberger, ed., Computers and the World of 
the Future, MIT Press, 1962, p. vii. Also see, for example, "The Project MAC Interviews," Annals of the History of Computing, vol. 14, no. 2, Apr.-June 1992, pp. 15-16.

26. Ibid., Greenberger, ed., Computers and the World of the Future, p. 205.

27. Ibid., p. 222.

28. J.C.R. Licklider, "Man-Computer Symbiosis," IRE Trans. Human Factors in Electronics, vol. 1, no. 1, Mar. 1960, pp. 4-11.

29. Ibid., p. 7.

30. J.C.R. Licklider, "Agenda for the study of library problems of the future," memo, box 6, folder "1961," Licklider Papers at MIT Libraries.

31. L. Beranek, "Roots of the Internet: A Personal History," pp. 60-61.

32. In Licklider Papers at MIT Libraries, box 7, folder "1963."

33. J.C.R. Licklider, Libraries of the Future, MIT Press, 1965, pp. 39-45.

34. Ibid., p. 42.

35. J.C.R. Licklider, "The Truly Sage System, or Toward A Man-Machine System for Thinking," manuscript, 20 Aug. 1957, box 6, folder "1957," Licklider Papers at MIT Libraries.

36. "The Project MAC Interviews," Annals of the History of Computing, vol. 14, no. 2, p. 16.

37. MIT Project Charles, "Problems of Air Defense: Final Report of Project Charles," MIT, Cambridge, Mass., 1951, 3 vols. See also, Redmond and Smith, From Whirlwind to MITRE, pp. 102-108.

38. Group Organization List of MIT Lincoln Laboratory, 1 July 1953; G. Miller, interview by C. Ishikawa Kita, 9 Oct. 2001, Princeton, N.J.; J.C.R. Licklider, $\mathrm{OH} 150$, oral history interview by W. Aspray and A. Norberg, transcript, 28 Oct. 1988, in Cambridge, Mass., Charles Babbage Inst., Univ. of Minnesota, Minneapolis, pp. 6-7.

39. See Ref. 36. Licklider interview by Aspray and Norberg, transcript, 1988, p. 10. Though he mentioned the computer as TX-2, it might be TX-0.

40. W. Clark, email interview by C. Ishikawa Kita, 24 June 2000.

41. Group Organization List of MIT Lincoln Laboratory, 1 July 1953. There were several informal meetings organized by Selfridge among people who were researching the function of the human brain through digital computers. Licklider joined the meetings. (W. Clark, email interview by C. Ishikawa Kita, 24 June 2000. Preliminary interview was done on 27 Mar. 2000, Palo Alto, Calif.) I confirmed the fact with Marvin Minsky, (email interview by C. Ishikawa Kita, 27 May 2000) and O. Selfridge, (interview, 23 Dec. 2000 , Cambridge, Mass.). Selfridge said that he could not recognize which meetings they were because he talked on the matter with a variety of people, including the people Clark suggested. Thus the fact that they had some relationship and talked about the "human brain and computer" can at least be counted as a historical fact.

42. The session of "Learning Machines," Proc. Western Joint Computer Conf., Inst. of Radio Engineers, 1955, pp. 85-111; O.G. Selfridge, "Pattern Recognition and Modern Computers," pp. 9193; G.P. Dinneen, "Programming Pattern Recognition," pp. 94-100.

43. Ibid., W.A. Clark and B.G. Farley, "Generalization of Pattern Recognition in a Self-Organizing System," pp. 86-91.

44. J.C.R. Licklider, "The Truly SAGE System," cover page.

45. Ibid., p. 8. Licklider used "information center" and "thinking center" interchangeably in the paper.

46. Project Charles and MIT Lincoln Laboratory were initiated by the US Air Force. Licklider served as a member of the Scientific Advisory Board, Office of the Chief of Staff, US Air Force, circa 1961.

47. "Man-Computer Symbiosis" (1960) was "supported largely by the Behavioral Science Division, Air Force Office of Scientific research, Air Research and Development Command," as indicated on the first page of the publication. Licklider, "Man-Computer Symbiosis," p. 4.

48. J.C.R. Licklider, "Truly SAGE system," p. 1.

49. Ibid., p. 2.

50. Ibid., p. 2-3.

51. Ibid., p. 3.

52. According to J. McCarthy, "Reminiscences on the History of Time-Sharing," Annals of the History of Computing, vol. 14, no. 1, Jan.-Mar. 1992, pp. 19-24. For more detail at MIT, see S.L. Garfinkel, Architects of the Information Society; Thirty-Five Years of the Laboratory for Computer Science at MIT, H. Abelson, ed., MIT Press, 1999, pp. 2-9.

53. J. McCarthy could not remember whether he had a conversation with Licklider before Sept. 1957 on "time-sharing." J. McCarthy, email interview by C. Ishikawa Kita, 30 Oct. 2001.

54. R.R. Everette, C.A. Zraket, and H.D. Bennington, "SAGE-A Data Processing System for Air Defense," Proc. Eastern Joint Computer Conf., Inst. of Radio Engineers, 1957, pp. 153-154.

55. J.A.N. Lee, "Time-Sharing at MIT: Introduction," Annals of the History of Computing, vol. 14, no. 1, Jan.-Mar. 1992, pp. 13-15. See also, J.A.N. Lee, "Claims to the Term "Time-Sharing," Ibid., pp. 16-17.

56. See, for example, A. Rosenberg, "Time-Sharing: A Status Report; Problems and Prospects," Datamation, Feb. 1966, vol. 12, no. 2, pp. 66-77.

57. J.C.R. Licklider, "Man-Computer Symbiosis: Part of the Oral Report of the 1958 NAS-ARDC Special Study, Presented on Behalf of the Committee on the Roles of Men in Future Air Force Systems, 20- 
21 November 1958," box 6, folder "1958," Licklider Papers at the MIT Libraries, pp. 2-3.

58. J.C.R. Licklider, "Man-Computer Symbiosis," 1960, p. 4.

59. J.C.R. Licklider, "The Truly SAGE System," p. 4

60. About Sabre, see for example, J.L. McKenney with D.C. Copeland and R.O. Mason, Waves of Change: Business Evolution through Information Technology, Harvard Business School Press, 1995. Especially, chapter 4: "Rattling SABRES: American Airlines and the Reservation System Revolution," pp. 97-140.

61. M. Campbell-Kelly and W. Aspray, "Computers," pp. 169-176.

62. Ibid., p. 174.

63. See, for example, A.L. Samuel, "Artificial Intelligence: A Frontier of Automation," The Annals of the American Academy of Political and Social Science, vol. 340, Mar. 1962, pp. 10-20.

64. Especially, the phrase "giant brain" was diffused by E.C. Berkeley, Giant Brains, or Machines that Think, John Wiley \& Sons, 1949.

65. J.C.R. Licklider, "The Truly SAGE System," p. 12.

66. M. Minsky homepage, http://www.ai.mit.edu/ people/minsky/people.html.

67. J. Bernstein, "Mind and Machine: Profile of Marvin Minsky," Science Observed, Basic Books, 1982, p. 29.

68. M. Minsky, email interview by C. Ishikawa Kita, 28 May 2000.

69. J. Bernstein, "Mind and Machine: Profile of Marvin Minsky," p. 101. The word the machine could recognize was not "watermelon" but "butterfat" according to G. Miller, interviewed by Ishikawa Kita, 2001.

70. According to H. von Foerster, ed., Cybernetics; Circular Causal and Feedback Mechanisms in Biological and Social Systems, vol. 7, Macy Foundation, New York, 1951, Licklider's talk was "The Manner in Which and Extent to Which Speech Can Be Distorted and Remain Intelligible." The best historical work on the meetings: S.J. Heims, Constructing $A$ Social Science for Postwar America: The Cybernetics Group, 1946-1953, MIT Press, 1991.

71. M. Mitchell Waldrop, Complexity, Simon \& Schuster, 1992, pp. 157-160.

72. D.O. Hebb, The Organization of Behavior, John Wiley \& Sons, 1949.

73. Licklider, "Man-Computer Symbiosis," 1960, p. 5.

74. C.T. Morgan et al., eds., Human Eng. Guide to Equipment Design, McGraw-Hill, 1961, p. 1.

75. J. Phinney Baxter 3rd, Scientist Against Time, Little, Brown, 1946, part five: "Men and Machines," pp. 395-417.

76. W. Sinaiko, ed., Selected Papers on Human Factors in the Design and Use of Control System, Dover Publications, 1961, p. vii.

77. E.J. McCormick, Human Engineering, McGrawHill, 1957.
78. See the section "Officers, Board, Committees, and Representatives of the American Psychological Association, 1957-1958," The American Psychologist, vol. 12, no. 11, p. 710.

79. Human Factors, vol. 1, no. 1, Sept. 1958 (it was issued in 1959).

80. "Proc. Sixty-Ninth Ann. Business Meeting," The American Psychologist, vol. 16, no. 12, p. 785.

81. J.C.R. Licklider, "Man-Computer Symbiosis: Part of the Oral Report of the 1958 NAS-ARDC Special Study," Licklider Papers at the MIT Libraries.

82. Ibid., front page.

83. Ibid., p. 2.

84. Ibid., pp. 4-7.

85. J.C.R. Licklider, "The Cerebral Frontier," 24 Apr. 1961, Licklider Papers at MIT Libraries, box 6, folder "1961," front page.

86. Inst. for Defense Analyses, "Computers in Command and Control," pp. 56-57.

87. J.C.R. Licklider, "Artificial Intelligence, Military Intelligence, and Command and Control," p. 133.

88. A. Norberg and J. O'Neill, Transforming Computer Technology, pp. 204-209.

89. Ibid., p. 14. Chapters two through five were dedicated for each of four research areas: time-sharing, computer graphics, networking, and Al.

90. See, for example, P.H. Salus, Casting the Net, Addison-Wesley, 1995, pp. 6-7; P.N. Edwards, The Closed World, MIT Press, 1996, pp. 262-271; K. Hafner and M. Lyon, Where Wizards Stay Up Late: The Origins of the Internet, Touchstone, 1996, pp. 24-40; M. Hauben and R. Hauben, Netizens: On the History and Impact of Usenet and the Internet, IEEE CS Press, 1997, chapter 6; T.P. Hughes, Rescuing Prometheus, Pantheon Books, 1998, pp. 258-265; J. Abbate, Inventing the Internet, MIT Press, 1999, pp. 43-44; and J. Naughton, A Brief History of the Future: The Origins of the Internet, Weidenfeld \& Nicolson, 1999, pp. 65-76.

91. I. Sutherland, "Computer Graphics: Ten Unsolved Problems," Datamation, vol. 12, no. 5, May 1966, pp. 22-27.

92. A. Norberg and J. O'Neill, Transforming Computer Technology, pp. 129-130.

93. L.G. Roberts, Graphical Communication in a TimeSharing Environment, tech. report, MIT Lincoln Laboratory, May 1965, p. 1. (This paper was presented at the 1965 IFIPS Congress, 24-29 May 1965, New York.)

94. I.E. Sutherland, "The Future of On-Line Systems," On-Line Computing Systems, E. Burgess, ed., proceedings of the symposium sponsored by the Univ. of California at Los Angeles and Informatics Inc., 2-4 Feb. 1965, American Data Processing, 1965, p. 13.

95. Macromodular Computer System project at Washington Univ. led by W. Clark from Mar. 1965, and Parallel Processor (ILLIAC IV) project at 
Univ. of Illinois led by D. Slotnick from Feb. 1966. See, for example, Norberg and O'Neill, Transforming Computer Technology, pp. 264-269.

96. I. Sutherland, $\mathrm{OH} 171$, oral history interview by W. Aspray, transcript, 1 May 1989, Pittsburgh, Charles Babbage Inst., Univ. of Minnesota, p. 20.

97. A. Norberg and J. O'Neill, Transforming Computer Technology, p. 264.

98. Ibid., pp. 204-209.

99. I. Sutherland, "The Future of On-line Systems," p. 11.

100. A. Norberg and J. O'Neill, Transforming Computer Technology, p. 116.

101. See, for example, A.G. Hammersmith, "Selecting a Vendor of Time-Shared Computer Services," Computers and Automation, vol. 17, no. 10, Oct. 1968, pp. 16-22; R.T. Bueschel, "Time Sharing in the Near Future," Computers and Automation, vol. 18, no. 1, Jan. 1969, pp. 28-30.

102. T.P. Hughes, Rescuing Prometheus, p. 265.

103. See, for example, R.A. MacGowan, "Small Scientific Computers versus Data Communications Systems in a Large Computer Environment," Computers and Automation, vol. 13, no. 2, Feb. 1964, pp. 26-28; M. Emerson, "The 'Small' Computer versus Time-Shared Systems," Computers and Automation, vol. 14, no. 9, Sept. 1965, pp. 18-20.

104. R.W. Taylor, "Man-Computer Input-Output Techniques," IRE Trans. Human Factors in Electronics, vol. 8, vol. HFE-8, no. 1, Mar. 1967, p. 2.

105. R.W. Taylor, "Plans for an Experimental, Interactive Computer Network," paper prepared for the 2nd Workshop on National Systems of the Task
Group on National Systems for Scientific and Technical Information, Front Royal, Va., circa 1968, pp. 9-10; Taylor's personal files.

106. T. Marill and L.G. Roberts, "Toward a Cooperative Network of Time-Shared Computers," AFIPS Conf. Proc. Fall Joint Computer Conf., Spartan Books, vol. 29, 1966, pp. 425-431.

107. L.G. Roberts, "The ARPANET and Computer Networks," A History of Personal Workstations, A. Goldberg, ed., ACM Press, 1988, pp. 143-144. 108. Ibid., p. 146.

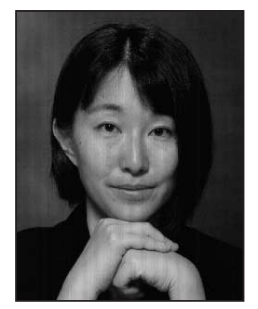

Chigusa Ishikawa Kita was granted a doctorate in 2002 from Kyoto University. Her research interests include the formation of technological vision and research agenda, the social impact of computing technology, and the process of institutionalization in the field of computer science. A book on the early history of the IPTO based on her dissertation was published in Japan in 2003.

Readers may contact Chigusa Ishikawa Kita at Academic Center for Computing and Media Studies, Kyoto University, Yoshida-Nihonmatsu-cyo, Sakyo, Kyoto, Japan 606-8501; chigusa.kita@nifty.ne.jp.

For further information on this or any other computing topic, please visit our Digital Library at http://computer.org/publications/dlib.
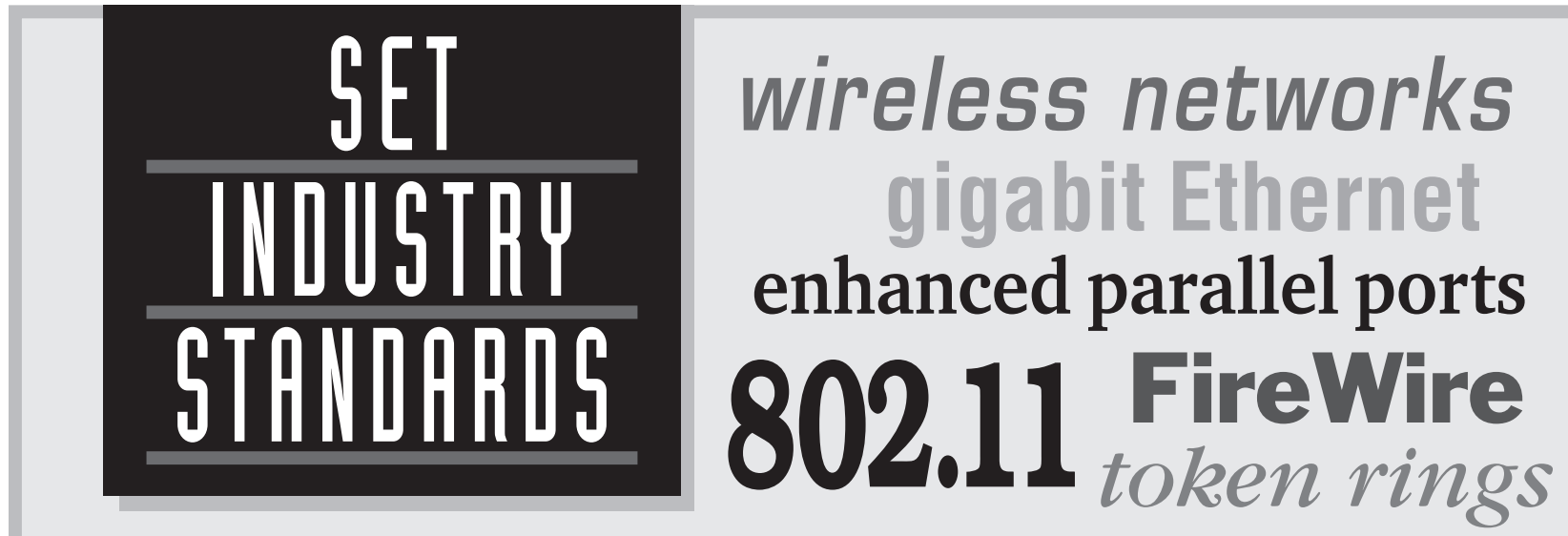

IEEE Computer Society members work together to define standards like IEEE 802, 1003, 1394, 1284, and many more.

HELP SHAPE FUTURE TECHNOLOGIES • JOIN AN IEEE COMPUTER SOCIETY STANDARDS WORHING GROUP AT computer.org/standards/ 